\title{
RESPIRATORY HAZARDS IN THE PREMATURE INFANT
}

\author{
By Albert E. Claireaux, M.D., M.R.C.P.E.
}

Pathologist, Bernhard Baron Memorial Research Laboratories, Queen Charlotte's Mate

Obstetrics and Gynaecology, Hammersmith Hospital

At birth the newborn infant is required to make an abrupt adjustment to a new environment. Hitherto its existence has been parasitic and its needs have been supplied by the maternal organism. The most immediate dramatic changes required to support extra uterine life are concerned with respiration and the circulation. The infant must achieve a regular respiratory rhythm and be able to expand its lungs fully. At the same time the blood flow through the pulmonary circulation must be adequate for the gaseous exchange to take place between the pulmonary capillaries and the lumen of the air spaces. The necessary adjustment is not achieved without difficulty in some mature infants and is an infinitely more serious problem for the premature infant. Any definition of prematurity has its drawbacks, but the most generally accepted criterion is a birth weight of under $2,500 \mathrm{~g}$. It is to be remembered that twins will be more advanced in their development than their birth weight would suggest and that certain races, such as the negroes, are more mature at a given weight than the white races. Morrison (1952) states that 50 per cent. of all twins are under $2,500 \mathrm{~g}$. at birth.

The premature infant is a much more puny specimen than is the offspring of a full-term pregnancy. It has a greater surface area in relation to its body weight and so tends to lose heat and fluid more easily. It has little subcutaneous fat and so its insulation is poor. Furthermore, the cause of prematurity may have some bearing on its chances of survival.

Pre-eclamptic toxaemia, ante-partum haemorrhage and rhesus iso-immunization of the mother may result in premature delivery. The first two disorders often result in the infant being severely affected by anoxia and the third causes the infant to be affected with haemolytic disease. Other maternal diseases, such as cardiac disease, tuberculosis and diabetes mellitus, may prevent the pregnancy from going to term and the infant suffers beyond the customary hazards of a premature delivery.
In many cases, perhaps as many as 40 per cent. there is no apparent cause for the interruption of 3 pregnancy, and the infant is delivered in a healthy' state, but is immature. It now has to assume an independent existence, and good respiratory function is vital. Unsatisfactory respiratory func- $\dot{c}$ tion is responsible for I 5 per cent. of deaths among $\mathscr{C}_{\infty}$ premature infants, according to Keeri-Szanto eto al. (1950). Among the very premature infants, 750-1,000 g. birth weight, Potter (1952) foundc that respiratory failure was responsible for death in 85 per cent. At Queen Charlotte's Hospital $\vec{\omega}$ we have found that respiratory dysfunction was $\frac{\mathrm{g}}{\mathrm{g}} \mathrm{t}$ least partly responsible for the death of 144 per cent.) of 193 premature infants of all rangeso of birth weight from $700-2,500 \mathrm{~g}$. Satisfactory respiratory function depends on the adequacy of the central nervous system, lungs and respiratory muscles and on the absence of pathological changes $\bigcirc$ which are likely to affect respiration.

\section{Central Nervous System}

Potter (1952) is of the opinion that immaturity of the respiratory centre is hardly ever responsibleo for the failure of the infant to breathe. Nevertheless, changes in the respiratory centre asso- $\frac{0}{3}$ ciated with prematurity may prevent the onset of a regular respiratory rhythm. Boutourline-Young and Smith (1950) have found that periodic

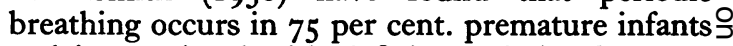
and is associated with definite periods of apnoea $>$ in 29 per cent. This tends to ensure that the average respiration rate in the premature infant is rather slower than that of the mature infant. Periodic type of respiration was also noted by ${ }^{\circ}$ Wilson, Long and Howard (1942), who ascribed $\omega$ it to an insufficient sensitivity of the respiratory centre to hydrogen ion stimulation. Keeri-o

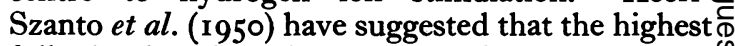
fully developed respiratory centre in the premature? infant is an inhibitory centre which normally damps down respiratory movements in the later

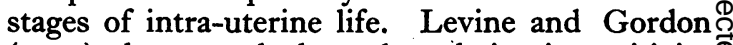
(I942) also remarked on the relative insensitivity 
of the immature respiratory centre to an increase in the $\mathrm{CO}_{2}$ content of respired air. They suggested that this might be the result either of incomplete nerve cell development or of poor capillary development in the medulla which would impede gaseous exchange. It would thus appear that the first hazard the premature infant has to overcome is a respiratory centre which is not yet fully adjusted to its new responsibilities.

\section{Thoracic Cage and Muscles of Respiration}

The premature infant has a feeble musculature and the bony thoracic cag $\epsilon$ is still very soft. Together these factors result in a reduced negative intra-thoracic pressure. This in turn reduces the efficiency with which the infant can expand its lungs. Furthermore, if the infant is experiencing respiratory difficulty, such as an obstruction to the flow of air into the bronchial tree, it has little reserve power to overcome such an obstacle. When the accessory muscles of respiration are called into play the thoracic cage tends to buckle under the strain. The premature infant with respiratory embarrassment shows marked rib recession and the whole sternum may be hollowed.

\section{Lungs}

The lungs are called upon to bear the brunt of the change from intra-uterine to extra-uterine life. In the premature infant they do so before they have reached the peak of their development. How well they can undertake their new function largely depends on how far they are able to promote gaseous exchange between the air in the alveoli and the blood in the pulmonary capillary bed. This in turn depends on how advanced the development of air spaces and capillary ingrowth has become.

The respiratory passages and lungs develop from an outgrowth from the ventral wall of the foregut about the end of the second week of pregnancy. A respiratory tube is formed whose caudal end divides into two and grows caudally into a mass of primitive mesenchyme. Pulmonary diverticula arise from the tube and subdivide, the right into three vesicles and the left into two. As these vesicles grow they carry with them a covering of mesoderm from which the blood vessels and other tissues are later derived. The entodermal cells lining the vesicles eventually develop into the epithelium of the respiratory passages. By repeated subdivisions of the primitive respiratory tube the entire bronchial tree is eventually formed. Finally the respiratory bronchioles and alveolar ducts appear. While the entoderm is branching the mesenchyme is becoming more differentiated. By the 2oth week capillary ingrowth is commencing and the epithelial cells are separated as

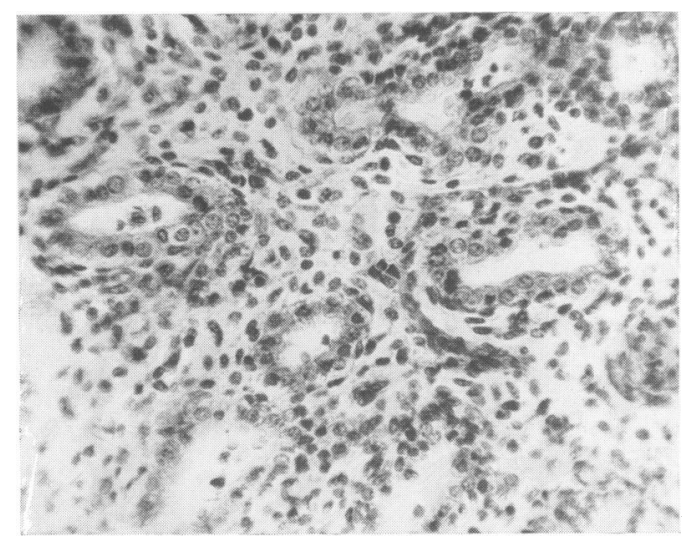

FIG.I-Lung from foetus of 20 weeks gestation. The air spaces are lined by cuboidal epithelium and are separated by primitive mesenchyme. Capillary ingrowth has just commenced. ( $\times 300$; all sections stained with haematoxylia and eosin).

the capillary loops pass towards the lumen of the future air spaces (Fig. I). At the same time there is differentiation of the mesoderm into connective tissue and elastic fibres. About the 28th week there is sufficient vascularization to allow independent existence, but each successive week increases the chances of the infant's survival. From the 28th week until term vascularization proceeds apace and true alveoli multiply on the alveolar ducts. There is thus a far more efficient system for oxygenation at term than there is at the 28th week when the infant may be deemed viable.

In addition to inadequate capillary ingrowth and differentiation into alveoli, Morrison (1952) believes that in premature infants there may be an accumulation of oedema fluid in the pulmonary interstititial tissue. This fluid may result from anoxia capillary damage and tends to 'splint' the lung, obstructing the free circulation of blood and hampering respiratory movements.

The efficiency of the infant's response to its changed circumstances at birth will depend to a considerable extent on how adequately fluid is removed from the air spaces at birth by the pulmonary circulation. Obviously, if the infant's lungs are waterlogged at birth there is likely to be some delay in full expansion and normal aeration. This will in turn lead to the development of anoxia and cyanosis, which will further retard the efficient removal of fluid from the air spaces. A vicious cycle is thus likely to ensue.

There has been considerable argument as to whether the infant exhibits movements comparable to respiration while still in utero. While an infant is in the uterus all the air passage 3 contain fluid. 
In the eariy stages of embryological development this fluid is probably a transudate from the surrounding tissues. At a later stage the foetus is rounded by liquor amnii and this fluid also is present in the air passages. The work of Snyder (1949) has suggested that rhythmic movements of the chest occur in utero and that infants actively draw amniotic fluid into their lungs before birth. Potter (1952) is in agreement with this opinion and Davis and Potter (1946) used thorotrast injected into the amniotic sac in an attempt to demonstrate that the foetus can inspire amniotic fluids. They were able to show that the lungs were outlined by the radio-opaque substance on X-ray examination after the birth of the infant. Windle (I94I), on the other hand, did not believe that the foetus normally inspires amniotic fluid and Morrison (1952) is also doubtful whether the movement of fluid in and out of the lungs in any way resembles the tidal movement of air in normal respiration. The latter criticizes experiments of Davis and Potter (1946) on the grounds that the radio-opaque colloid substance used will diffuse readily throughout the entire volume of amniotic fluid including that portion in the lungs without the aid of active inspiration.

Solid debris from the amniotic sac, such as particles of vernix caseosa and cornified cells, is found scattered throughout the lungs in most stillborn foetuses and of infants who die shortly after birth. Its dispersal is rather irregular and is not entirely consistent with a respiratory flow of amniotic fluid. As will be seen later, large quantities of solid debris in the lungs of newborn infants is usually associated with active respiratory movements caused by anoxia. Whatever the mechanism by which fluid enters the air spaces of the lung any large amount will embarrass the respiratory activity of the infant at birth. The adult animal can absorb fluid extremely rapidly into the pulmonary circulation (Potter, 1952). The infant's pulmonary circulation is, however, much less effective and the greater the degree of prematurity the greater the embarrassment caused by fluid in the lungs.

\section{Lung Pathology in the Premature Infant}

It has been shown that many of the respiratory hazards in the premature infant derive directly from a state of immaturity of the respiratory apparatus itself. Further respiratory embarrassment is likely to occur if pathological changes develop in the infant.

\section{Effects of Anoxia}

Anoxia is not infrequently associated with a sudden catastrophe, such as a premature separation of the placenta. The infant may die of asphyxia before delivery or may be born with the effects of severe anoxia. If the anoxia develops $\frac{3}{8}$

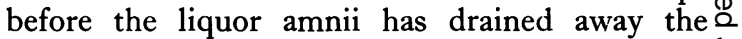

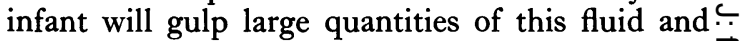
amniotic debris down into its lungs. The debris $\overrightarrow{\vec{F}}$ consists largely of squames and some vernix caseosa. Even if the infant has apparently failed to breathe the lungs will be partially expanded $\overline{\bar{\omega}}$ by the fluid and in the lumen of the air spaces $\vec{\Phi}$ large quantities of amniotic sac contents will be $\varrho$ found. With more severe anoxia the anal sphincter $\tilde{N}$ relaxes and meconium is passed into the liquor. $\overrightarrow{0}$ This meconium may also be aspirated and is especially dangerous as it is so viscid. Once $\vec{\omega}$ meconium is aspirated into the bronchial tree it is almost impossible to get it out again. It causes $\frac{O}{3}$ blockage of the airway and the infant may die from suffocation. If large quantities of liquor amnii, with or without meconium, are aspirated ${ }_{A}^{\omega}$ into the lungs the infant may die as a result of drowning in its own liquor. The infant may $\mathcal{L}_{\infty}$ survive the effects of anoxia and waterlogging of $\circ$ its lungs only to be overtaken by pneumonia resulting from the aspiration of infected liquor amnii or of meconium. The latter is thought by some workers to be a lung irritant and this may $\overrightarrow{0}$ be the result of the presence of enzymes. Squames, of cornified cells and vernix debris have been foun to set up a giant-cell reaction in the lungs of adific rabbits (Cruickshank, I949), but in the infants lung they probably produce little in the way of an inflammatory reaction unless the liquor is infected.

\section{Pulmonary Haemorrhage}

The asphyxiated infant, whether premature or $\bar{P}$ born at term, usually shows numerous petechialo haemorrhages below the pleura over both lungs. 을 These are agonal haemorrhages resulting from 3 . anoxia. According to Potter (1952) they are especially numerous in association with anoxia caused by premature separation of the placenta. $\delta$ They are also found over the thymus, heart and $₹$ mediastinum. Haemorrhages into the interstitialo tissue of the lungs are also largely the result of $\square$ vascular damage caused by anoxia and are most을. frequently found in the stillborn asphyxiated $\bar{N}$ foetus. They are, however, occasionally seen in the liveborn premature infant. The extravasated 0 blood is usually seen in the connective tissue ${ }_{\omega}^{N}$ round the bronchi and large blood vessels, but the alveoli are free from red cells. In the prematureo infant, however, a most devastating type of haemorrhage is found. This is known as massive $\stackrel{\oplus}{+}$ intra-alveolar haemorrhage. The haemorrhage 0 occurs either in the first few hours or first fewo days after birth and, except when associated with haemolytic disease, it is seldom found in the 


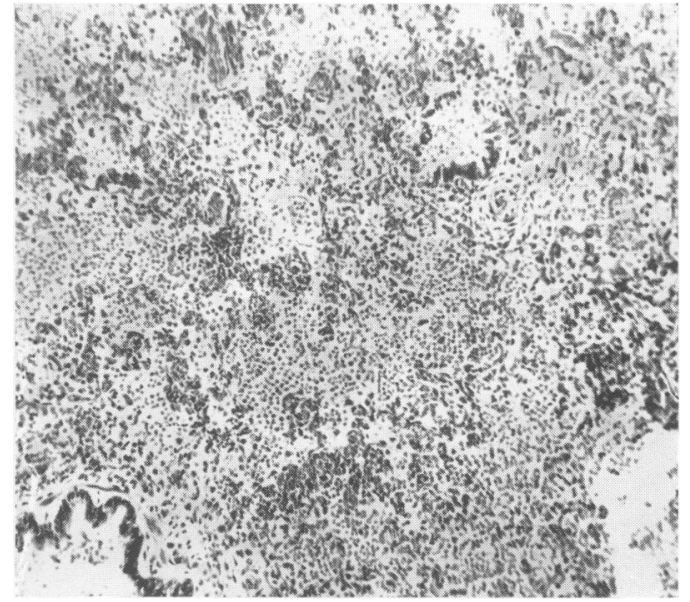

FIG. 2.-Lung of premature infant showing massive intra-alveolar haemorrhage. $(\times 300)$.

mature infant. The infant may be progressing quite well when suddenly it pours blood from the nostrils and becomes cyanosed. In effect it drowns in its own blood. Post-mortem the lungs have a striking appearance. They are dark-red and almost as firm as in pneumonic consolidation. On slicing blood oozes from the cut surface and the trachea and bronchi contain fresh fluid blood. Histologically all the alveoli in practically every section of lung are flooded with red cells (Fig. 2). Blood is also present in the alveolar ducts, and bronchi.

The cause of this massive haemorrhage is unknown. It is believed by some to be the result of infection and is sometimes called a haemorrhagic pneumonia. The infectious agent is thought to attack the pulmonary capillary walls in the first instance. These walls rupture and lead to a sudden fatal haemorrhage before there is time for an inflammatory reaction to develop. No infectious agent has yet been incriminated although a virus has been suspected. Others believe it may result from haemorrhagic disease caused by a deficient of vitamin $\mathrm{K}$ leading to hypoprothrombinaemia. There is, however, seldom any evidence of bleeding elsewhere in the body in these patients. At the moment the majority of workers regard the haemorrhage as the result of a pulmonary capillary injury by anoxia. Macgregor (I939) reported I 3 cases with this lesion; seven were premature. She was not convinced of the role of infection in the etiology of the condition.

\section{Emphysema and Pneumothorax}

The lungs of the premature infant are fragile and acute overdistension of the air spaces may lead to rupture of the alveolar walls and to the formation of emphysematous bullae. In a severe case these bullae will be found lying subpleurally over the entire surface of both lungs. In less severe cases they are often limited to the anterior lung border. The bullae vary in size from a pinhead to several millimeteres in diameter. These bullae may rupture into the pleural cavity with the production of a pneumothorax which may lead to the death of the infant if the air is not removed. Mild degrees of pneumothorax are probably not uncommon. When the alveolar walls rupture the air may pass into the interstitial tissue of the lungs and track along the bronchovascular spaces to the lung hilum and anterior mediastinum or up into the subcutaneous tissues of the neck. This interstitial form of emphysema may cause considerable respiratory distress and surprisingly large volumes of air may be involved. I have seen the thymus 'floating' on top of a bubble of air fully $3 \mathrm{~cm}$. in diameter in the connective tissue of the anterior mediastinum.

The cause of emphysema in the neonatal lungs is unfortunately often the result of rather heroic attempts at resuscitation. This is especially true of emphysema of the anterior borders of the lungs. These areas seem to be the most easily inflated and also the most easily overinflated. If a lung is only poorly expanded, these areas will expand with moderate pressure of air. A further increase in pressure will not necessarily expand the still refractory bulk of the lung, but will very often induce emphysema in the narrow strip already aerated. It must not be thought, however, that artificial respiration is the only source of damage. It has been already mentioned that aspiration of meconium is very liable to result in bronchial obstruction. The premature infant's own efforts to overcome such an obstruction can result in the development of widespread emphysema.

\section{Atelectasis}

There has been a good deal of confusion as to what is meant by the terms 'atelectasis' and 'collapse' when applied to the neonatal lung. Indeed Morrison (1952) prefers to use the terms 'initial non-aeration and non-expansion' to describe areas in the lungs which have not been aerated. On the other hand, Potter (1952) prefers the term atelectasis. She defines primary atelectasis as the state of the lungs before respiration has been established. This is the state of the lungs of stillbirths and that author believes it is seldom present in the lungs of infants who have ever breathed normally. Secondary atelectasis (sometimes called resorption atelectasis) is the result of the collapse of alveoli which have once been expanded with air. The alveoli, especially 
in the lungs of premature infants, have little elasticity and contain little residual air. What little air there is tends to be absorbed during the infant's death agony and postmortem the lungs appear airless.

Even careful histological examination may fail to determine whether an area of lung has been aerated. In general, non-aerated lung contains a little faintly acidophile fluid and the alveolar walls are not in opposition and the pattern is regular throughout. Unfortunately this appearance may be mimicked by the development of pulmonary oedema in a lung which has been expanded. While the lung is still developing, the air spaces are lined by cuboidal epithelial cells. These cells have almost entirely disappeared at term, but are still present in the lung of the premature infant and are more easily recognizable in the very immature. When the fluid in the air spaces is replaced by air and the alveoli expand, these cells, except in the very immature lung, are impossible to detect. If they are clearly recognizable in the walls of air spaces and have apparently not undergone any change, then air has probably not entered these areas. It is not always easy, however, to give a definite opinion on some sections.

In the lung of the premature infant who dies in the first few days of extra-uterine life, the pattern of atelectasis is very distinctive (Fig. 3). The great bulk of the lung is collapsed and the few areas which show aeration, chiefly the alveolar ducts, are grossly overdistended, but a few show acute vesicular and interstitial emphysema. A frequently associated finding with this type of atelectasis is hyaline-membrane formation.

\section{Hyaline-Membrane Formation}

Atelectasis is the most important single cause of death in the premature infant. Of the 193 deaths among premature infants in this series ro9 $(56$ per cent.) were attributable to atelectasis. Of these rog cases of atelectasis 57 were associated with hyaline-membrane formation. In a series of 108 infants with hyaline-membrane which was reported recently (Claireaux, 1953) it was found that 80 per cent. had developed in premature infants. One in every five of these infants had been delivered by Caesarean section. This association between hyaline-membrane development and Caesarean section was also noted by Potter (1952).

Infants with atelectasis and hyaline-membrane often have had difficulty in establishing respiration at birth. Air entry over the lung fields is poor and marked sternal and rib-recession develops. Cyanotic attacks become more frequent and the infant usually diss in $24-48$ hours of birth.

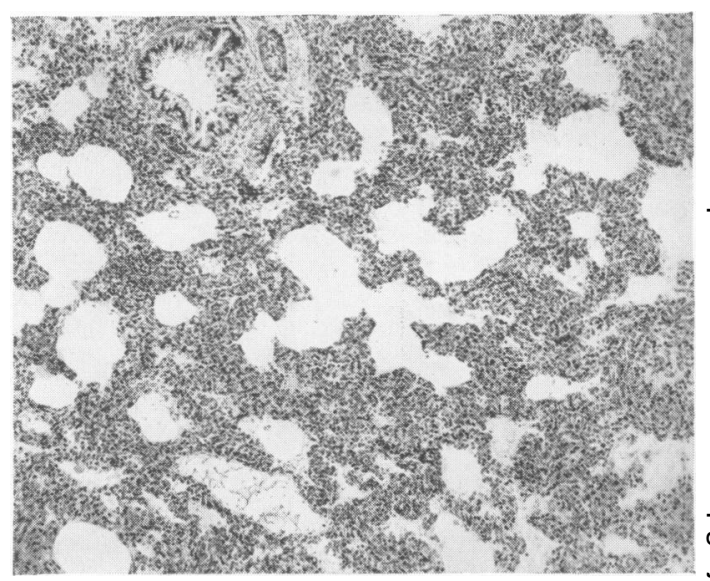

FIG. 3.-Lung of premature infant showing widespread atelectasis with overdistension of alveolar ducts. $\left(\times_{100)}\right.$.

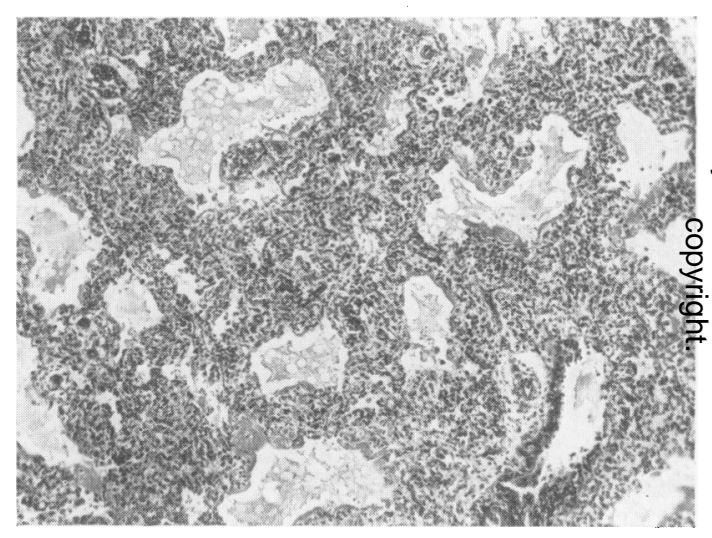

FIG. 4.-Lung of premature infant showing the pattern of atelectasis. The overdistended alveolar ducts in this lung are lined by acidophil hyaline-membrane. ( $X_{\text {IOO) }}$.

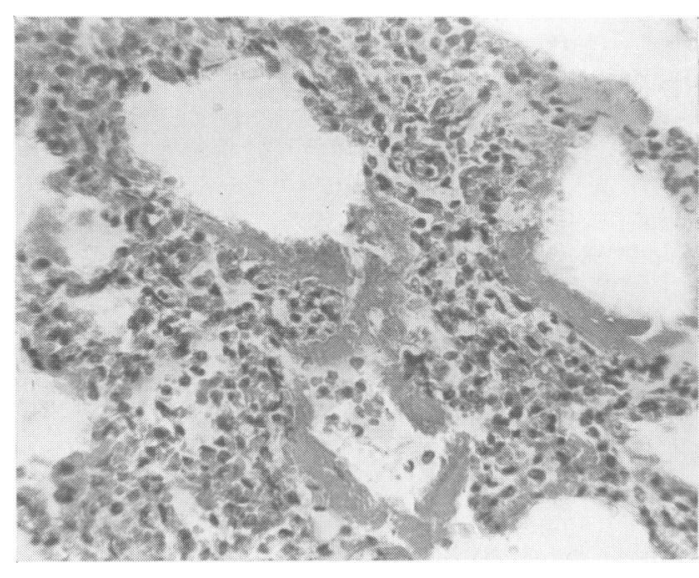

FIG. 5.-Lung of premature infant showing alveoli lined by hyaline-membrane. $\left(\times_{400}\right)$.

\section{o \\ $\omega_{\infty}^{\infty}$


At post-mortem examination the lungs are bulky and dark-red; they show little evidence of aeration and sink when placed in water. On being sliced they are found to have the consistence of liver. The lungs have a striking appearance on histological examination. There is widespread atelectasis which has a similar pattern to that already described (Fig. 3), but in this instance the overdistended alveolar ducts and respiratory bronchioles are lined by a dense, acidophile, hyaline material (Fig. 4). This material is the so-called hyaline-membrane (Fig. 5). It occasionally contains fat. It does not stain for fibrin and gives a weakly positive reaction with the periodic acid-Schiff technique. This indicates that a polysaccharide is one of its constituents. An extensive histochemical study has been reported by Lelong, Laumonier and Le Tan Vinh (1953), but the exact nature of this material is still obscure.

Hyaline-membrane formation was first described in detail by Johnson and Meyer (1925). These authors believed the condition was associated with the aspiration of amniotic sac contents. Farber and Sweet (I93I) suggested that the membrane was formed as a result of aspiration of vernix membrane since it gave a positive reaction for fat. Blystad et al. (I95I) reported the experimental production of a hyaline-membrane in animals by injecting large quantities of liquor amnii. These authors believed that the protein in amniotic fluid is gradually laid down as a membrane lining the walls of the air spaces while the fluid is absorbed into the pulmonary circulation. Not all the workers in this field are convinced that the membranes are the result of aspiration of amniotic fluid and debris. Miller et al. (195I) produced a hyaline-membrane in rabbits by resection of the vagus and Bruns and Shields (195I) showed that guinea-pigs maintained in high concentration of oxygen for many hours died from respiratory embarrassment and a hyaline-membrane was present in their lungs.

Lelong, Laumonier and Le Tan Vinh (1953) do not believe in the aspiration theory and point out that similar membranes have been described in the lungs of older children dying as a result of influenza, rheumatic carditis, interstitial plasma cell pneumonia and aspiration of milk. They believe that these membranes are the result of exudation from the pulmonary capillary bed into the air spaces. The various theories are critically reviewed by Tran-Dinh De and Anderson (I953).

Bovet du Bois (I95I) and Tregillus (I95I) thought that cellular degeneration of the epithelium lining of the lungs played a part in the formation of the membrane. Tregillus suggested that, as a result of anoxia, the epithelium of the terminal bronchioles underwent a degenerative

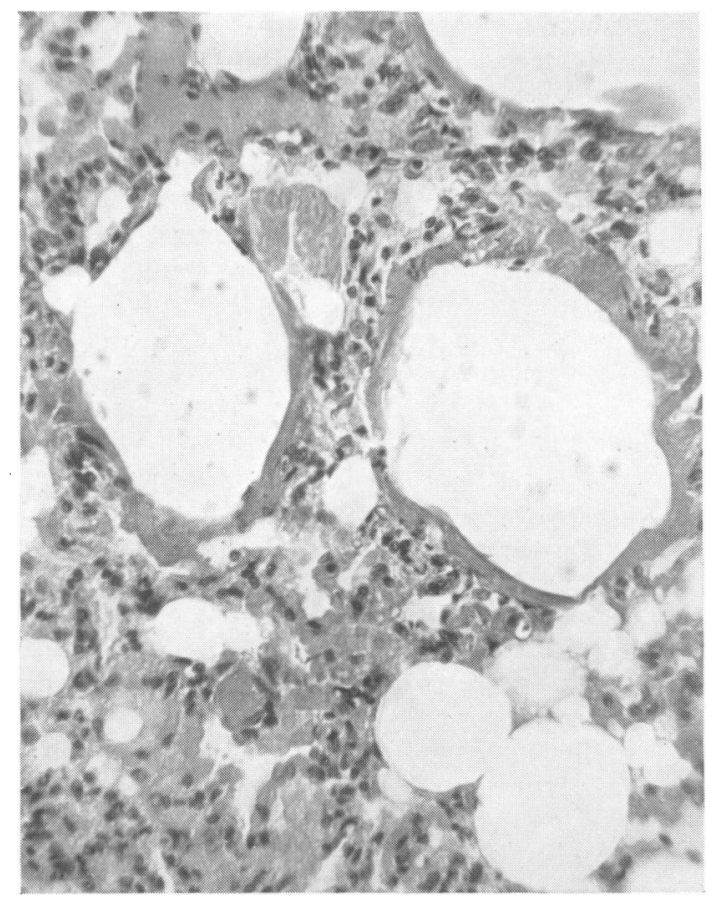

FIG. 6.-Rat lung 3 hours after intratracheal injection of meconium from a premature infant. A number of alveoli are lined by an acidophil hyaline-membrane. $(\times 400)$.

change and became hyalinized. He pointed out that the portions of the terminal bronchioles covered by membrane were denuded of epithelium, and that nuclear remnants could be demonstrated in the hyaline material. In a recent study (Claireaux, I953) I also observed that in some areas the membrane had a cellular appearance. In these areas the cells appeared to be hyalinized squames which had clumped together and finally fused to form an acidophile membrane. On account of this observation squames from human liquor amnii were hyalinized in vitro and injected intratracheally into rats. By this technique a hyaline membrane was produced in four out of six rats. The fact that the membrane is known to contain a polysaccharide suggested that meconium, which is especially rich in polysaccharide, might also be used to produce a membrane. Using a similar technique to that described above, meconium derived from a premature infant was injected intratracheally into six rats and the latter were killed after three hours. A hyaline-membrane was produced in all rats (Fig. 6). It thus appears that a hyaline-membrane can be produced in the lungs of an experimental animal in a variety of ways. Indeed, it is possible to criticize such 
experiments for that very reason. If you inject a hyaline material into the lungs of an animal it would be surprising if you did not get a ' hyalinemembrane' since the latter is formed by the dispersal of the hyaline material round the walls of the air passages by the pressure of air.

Whichever theory of the formation of hyalinemembrane, that of aspiration of amniotic sac contents or of exudation from the pulmonary vascular bed, is adopted it must take certain facts into consideration.

(i) The membrane has been found to contain fat and a polysaccharide.

(ii) It is clearly associated with cellular elements which appear to be undergoing hyalinization and are not merely debris caught up in the membranous material.

(iii) In addition to the membrane, large plugs of hyaline material are found which are often sufficiently large to fill completely an alveolar duct or respiratory bronchiole. It is difficult to believe that an exudate can satisfactorily explain all these occurrences. The clinical importance of the hyaline-membrane is also difficult to assess and recently Gruenwald (1953) suggested that it might be an 'eosinophilic herring.' Certainly, when nearly every alveolar duct in every lung field is lined by this membrane it is easy to conceive that it hinders gaseous exchange and may prevent air from reaching the distal alveoli which then collapse. But in other cases the membrane is thin and scattered and it is difficult to believe it is solely responsible for the death of the infant. Also it has been shown that a similar pattern of atelectasis can occur in the absence of a membrane (Fig. 3). In this series of rog cases of atelectasis in premature infants 57 had hyalinemembrane formation and 52 had none.

\section{Pneumonia}

Pneumonia is a less frequent complication of neonatal life than it was thirty years ago when a number of studies were made on this subject (Browne, I921, I922; Johnson and Meyer, I925). Since then the improvement in postnatal care of the infant and the use of antibiotics has greatly reduced the incidence of pulmonary infections. Nevertheless, it is still a serious problem in the premature infant. Macgregor (1939), in a large series of neonatal pneumonia, observed that premature babies are especially susceptible to infections of the respiratory tract.

(a) Pneumonia of intra-uterine origin. This type of pneumonia is associated with the aspiration of infected amniotic sac contents. It occurs in both the mature and premature infant and is usually associated with foetal anoxia during labour which has resulted in the stimulation of respiratory

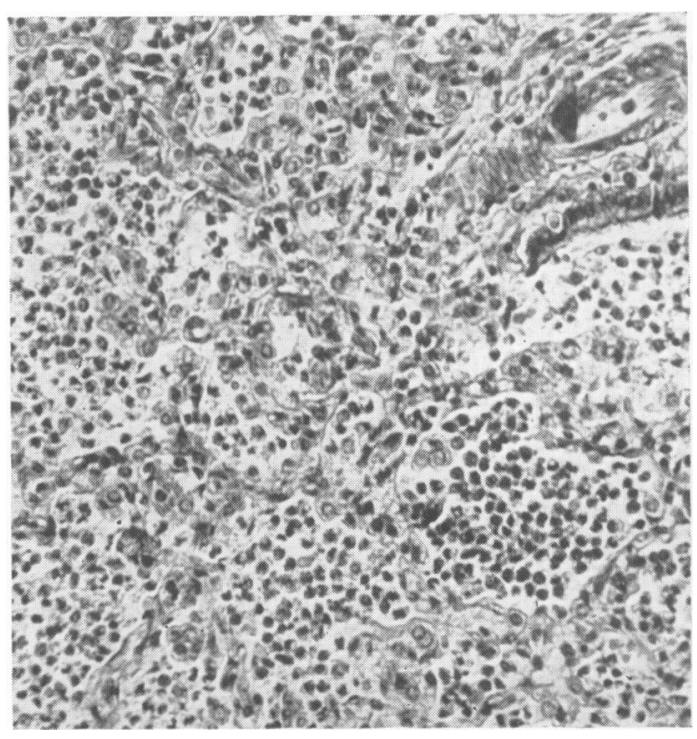

FIG. 7.- Lung of premature infant showing pneumonia. A cellular exudate with numerous polymorphonuclear leucocytes is present in bronchiole and surrounding alveoli. ( $\times$ 100).

movements and the aspiration of fluid. The pneumonia develops in the first few days of life. At post-mortem examination the lungs are bulky:it is often impossible to distinguish between patches of pneumonia and areas of collapse. The diagnosis depends on histological examination of the lungs. The latter reveals a picture similar to $\overrightarrow{\overrightarrow{0}}$ that of intra-uterine pneumonia in the stillborn $\frac{0}{3}$ infant. There is a diffuse leucocyte reaction in $\vec{\partial}$ the air spaces and alevolar walls. The leucocytes are mixed with amniotic debris and occasional $\frac{\partial}{0}$ clumps of bacteria. Red cells may be extravasated into the air spaces, but fibrin is scanty. Occasionally plugs of meconium are found.

(b) Pneumonia developing in the Neonatal Period. Pneumococcal lobar pneumonia of the type found in the older child and in the adult is seldom seen $\mathrm{S}$ in the neonate. A bronchopneumonia is the usual form, but is liable to become confluent and resembles lobar pneumonia on macroscopic examina- N tion. The organisms responsible include B- O haemolytic streptococcus, Streptococcus viridans, N $\mathrm{H}$. influenzae, staphylococcus aureus and Bact. $N$ coli. Pneumonias resulting from staphylococcal 0 infection are especially liable to show lung abscess formation and empyema is not uncommon.

Histologically the pulmonary lesion is found to commence with a leucocytic infiltration of the 7 peribronchial tissues and this spreads outwards into the alveoli. The alveolar exudate contains fibrin as well as polymorphonuclear leucocytes 
and histiocytes (Fig. 7). There is intense vascular congestion of the pulmonary vessels and interstitial oedema frequently develops. In the very premature infant, in addition to the leucocytic reaction, the walls of the alveolar ducts and terminal air spaces are lined by large mononuclear cells which resemble macrophages. Some investigators have suggested that these cells are normally lining the alveolar spaces, but only become visible when infection occurs. There is, however, no actual proof of this contention (Potter, 1952).

(c) Aspiration Pneumonia. The respiratory difficulties which the premature infant experiences makes him especially susceptible to aspiration of gastric contents and the development of a particular form of pneumonia. This form of pneumonia has been described in detail by Rhaney and Macgregor (I948). These authors reported $4 \mathrm{I}$ cases of this condition and found that 33 ( 80 per cent.) of the infants were premature. The lungs are consolidated and areas of haemorrhage are frequently seen. Pus may be expressed from the cut ends of the intrapulmonary bronchi and occasionally small abscesses are visible. On histological examination the bronchi are seen to be heavily infected and masses of bacteria are found among the dense cellular exudate. Digestion of bronchial and alveolar walls occurs as a result of the action of gastric juice. The red blood cells present in the exudate present a striking and characteristic appearance. 'They are lysed and the corpuscular envelope stains but feebly with eosin.

(d) Virus Pneumonia. Adams (1943) reported an epidemic form of respiratory tract infection in infants in Minneapolis. The mortality was 83 per cent. among the premature infants and only 8 per cent. in the mature group. The disease, which is thought to be the result of a virus infection, is characterized by a cough, dyspnoea and cyanosis with a moderate febrile condition. The bronchial epithelium tends to slough and the peribronchial and interstitial connective tissue of the lung is infiltrated with mononuclear cells. Cytoplasmic inclusion bodies $3-6 \mu$ in diameter were found in the bronchial epithelial cells and also in throat smears. The lungs were oedematous and haemorrhagic. It is possible that some other viruses may cause a haemorrhagic bronchopneumonia in the neonate.

(e) Interstitial Plasma Cell Pneumonia. This is a condition which occurs in premature infants between the sixth and eighth week of life. It has been reported in some countries in the Middle East and has made its appearance in Europe in the last few years (Martin Du Pan and Roulet, 1945). It is a disease of unknown origin and a virus etiology is suspected. The histological
FIG. 8.-Brain of premature infant showing a large blood clot in the left lateral ventricle. Some blood is also present in the subarachnoid space near the frontal pole.

appearance of the lung reveals a dense infiltration of the interstitial tissue with plasma cells. The picture is not dissimilar to that seen in syphilitic pneumonia alba. The disease has not yet been reported in England.

\section{Pathological Changes in the Central Nervous System}

Disorder of respiratory rhythm associated with immaturity of the respiratory centre and poor capillary development in the medulla has already been mentioned. Certain pathological changes may be found in the brain of the premature infant.

\section{Intracerebral Haemorrhage}

Severe anoxia during delivery, especially if associated with premature separation of the placenta, will produce haemorrhages into the brain substance. These haemorrhages are small perivascular petechial haemorrhages and are similar to those found over the lungs and thymus. These are scattered throughout the brain substance, but are especially numerous in the regions surrounding the the ventricles.

Occasionally very severe intracerebral haemorrhages occur and the blood disrupts a large portion of the brain and may burst inwards into the ventricles or outwards into the subarachnoid space. This type is usually the result of cerebral venous thrombosis complicating pneumonia or sepsis.

\section{Intraventricular Haemorrhage}

This is a lesion which is practically confined to the premature infant and is almost invariably associated with respiratory embarrassment. The entire ventricular system may be affected and the ventricles are occupied by fluid blood and blood 
clot (Fig. 8). These severe haemorrhages are the result of the rupture of subependymal haemorrhages into the ventricles. The original intracerebral haemorrhage may be quite small. It spreads through the soft immature glia of the subependymal region or forms a large blister beneath the ependymal epithelium. Eventually the blister bursts and blood escapes into the ventricles. 'The original haemorrhage into the brain is probably anoxic in origin and similar to that described above. There is no evidence that birth trauma plays any part in the production of these haemorrhages. They probably arise from a failure of the immature vessels to withstand congestion. The severe intraventricular haemorrhage is incompatible with life, but a low leak into the interventricular system may be supported for some days. The time of onset of such a haemorrhage is uncertain. Some probably develop as a result of antepartum anoxia. Others are associated with atelectasis, often complicated by hyaline-membrane formation, in the neonatal period. The haemorrhage further depresses respiration and a vicious cycle is initiated.

\section{Subarachnoid Haemorrhage}

When extensive, subarachnoid haemorrhage is usually the result of a massive interventricular haemorrhage where blood has escaped from the fourth ventricle into the cisterna magna. Small localized patches of haemorrhage in the subarachnoid space are not uncommon in the premature infant and result from anoxia.

\section{Subdural Haemorrhage}

This form of haemorrhage, resulting from birth trauma, with tears of falx and tentorium, is much less common in the premature infant than the other examples cited previously. When severe it is fatal and even small amounts of blood beneath the tentorium interfere with the vital centres.

\section{Diagnosis}

The diagnosis of a respiratory disorder is a matter of difficulty in any newborn infant and is even less easy in the premature. Differentiation between atelectasis and a cerebral haemorrhage may be impossible and as has been mentioned they may co-exist. Atelectasis results in cyanosis and the development of cerebral anoxia with symptoms apparently referable to the central nervous system. A cerebral or subdural haemorrhage may depress respiratory activity and signs of poor air entry are found in the chest. Atelectasis is suspected if the infant shows increasing dyspnoea with cyanosis, grunting respiration and rib or sternal recession. Attacks of apnoea occur. In infections of the lungs changes in temperature may be of little diagnostic value and chest sounds are apt to be misleading. A blood culture may $\frac{\pi}{\mathbb{2}}$ be of value if an infection is suspected, but nowa- $\varrho$ days many premature infants are given antibiotic therapy as a prophylactic measure from birth, especially if respiratory disorder is anticipated.

Radiological examination is of considerable $\frac{}{0}$ value, however, and with careful interpretation a firm diagnosis may be made. In interstitial $\widehat{\phi}$ emphysema and pneumothorax, X-ray examination will reveal the presence of air in the medias- $\infty$ tinum or pleural cavity. Recently a radiographic $\vec{O}$ study by Donald and Steiner (1953) has shown $\overrightarrow{\vec{\omega}}$ that it is possible to assess the degree of atelectasis ${ }_{\sigma}^{\omega}$ present in the neonatal lung and to make a diag- $\frac{D}{0}$ nosis of hyaline-membrane formation during life. 3 This condition has hitherto only been diagnosed after post-mortem examination. These authors distinguish three main types of change in atelec- $A$ tasis: (I) A fine mottling more or less uniformly $\dot{\omega}$ distributed throughout the lung fields. This is $\mathscr{\infty}_{\infty}$ probably due to diffuse alveolar collapse. (2) Theo fine mottling becomes coarser and tends to become coalescent. (3) Finally the shadows become con- $c$ fluent and collapse is recognizable. Once the coarse mottling and collapse have appeared the $\vec{\oplus}$ bronchial tree is seen to be clearly outlined. Thios on sequence of events seems to occur chiefly when : atelectasis is associated with hyaline-membrame formation.

Spirometry might also prove a useful adjunct to the diagnosis of respiratory disorders in the $\frac{0}{\mathbb{D}}$ premature infant, but it is very difficult to derive a method which is simple to use but which does $\overrightarrow{\overrightarrow{0}}$ not of itself tend to interfere with the infant's 3 respiratory activity.

It is not yet certain how long the normal infant? takes to expand its lungs fully. Potter (1952)흠 believes that the entire lung expands immediately after birth under normal conditions, and that allo the air spaces are expanded in the first few. moments after birth. Clement Smith (1946), on the other hand, has suggested that the lungs of $a$ newborn infant expand gradually over the first 음 few days of life. He believes that the lung opens $>$ rather like a fan, commencing with the easily․ㅡ. expandible anterior borders. I believe that then lungs of a normal mature infant expand immediately and completely within a short time of 0 birth. In the premature infant, however, thew poorly developed respiratory apparatus has pro-응 bably to achieve its goal by stages. The moreo easily expanded portions tend to become over-市 distended while the distal air spaces remain col-? lapsed. Further information on this subject is desirable since atelectasis is now the chief single cause of death in the premature infant. In general, if the premature infant shows complete $\stackrel{\mathbb{\Omega}}{\stackrel{\mathbb{}}{ }}$ 
expansion of both lungs on radiological examination shortly after birth it is unlikely to develop progressive atelectasis with or without hyalinemembrane formation.

\section{Treatment}

Since an accurate diagnosis is only arrived at with difficulty, the treatment of respiratory disorders in the premature infant must of necessity be somewhat empirical. Heat loss is prevented and oxygen is administered in an incubator and later infection is largely prevented by cubicle nursing. A clear airway is essential and mucus and fluid must be extracted immediately after birth. Premature infants and infants delivered by Caesarean section are inclined to bring up very large quantities of mucus and fluid from their lungs (Bloxsom, 1953). It is these infants which are especially liable to develop atelectasis with hyaline-membrane formation (Claireaux, 1953).

Some authorities believe that, if the membranes are known to have been ruptured for some time and if the infant is thought to have aspirated amniotic fluid, antibiotics, such as penicillin and streptomycin should be exhibited as a prophylactic measure. All possible means should be taken to prevent infection in the neonatal period as premature infants are especially susceptible, and chemotherapy and antibiotic therapy is at once instituted if pneumonia develops.

The treatment of atelectasis is a more complex problem. The chief anxiety is to see that the infant receives as much oxygen as it requires to maintain life by the most effective means. Recently Donald and Lord (1953) have described an apparatus which they have used to resuscitate premature infants after birth. They believe that atelectasis with hyaline-membrane formation is a reversible condition provided the most energetic attempts are made to ensure an adequate supply of oxygen to the lungs within the first few hours of life. It is by such improved methods of resus-气 citation in the newborn premature infant that $\frac{3}{\Phi}$ success is likely to be attained in the treatment of $\cong$ the all-important condition of atelectasis.

\section{BIBLIOGRAPHY}

ADAMS, J. M. (1943), 7. Pediat., 23, 189.

BLOXSOM, A. (1953), Amer. F. Obstet. Gynec., 66, 1172.

BLYSTAD, W., LANDING, B. H., and SMITH, C. A. (1951), Pediatrics, 8, 5.

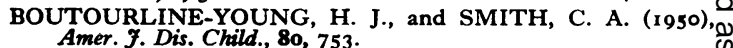
BOVET DU BOIS, N. (195I), Rec. Suisse Path. et Bact., 14, 26 r. BROWNE, F. J. (1922), Brit. med. F., 1, 469, 2, 590.

BROWNE, F. J. (1921), Edinb. med. F., $27,153$.

BRUNS, P. D., and SHIELDS, L. V. (1951), Amer. F. Obstet.c. Gynec., 61, 953.

CLAIREAUX, A. E. (1953), Lancet, ii, 749.

CRUICKSHANK, A. H. (1949), F. Path. Bact., 61, 527.

DAVIS, M. E., and POTTER, E. L. (1946), Ұ. Amer. med. Assoc. 131, 1 I 94 .

DONALD, I., and LORD, J. (1953), Lancet, i, 9.

DONALD, I., and STEINER, R. E. (1953), Ibid., ii, 846.

FARBER, S., and SWEET, L. K. (1931), Amer. F. Dis. Child.,

GRUENWALD, P. (1953), Report of Fifth M. and R. Pediatric

JOHNSON, W. C., and MEYER, J. R. (1925), Amer. F. Obstet.O Gynec., 9, $15 \mathrm{I}$.

KEERI-SZANTO, M., HUSZAR, A., KEPES-KUDAS, B., andCIRAKY, G. (1950), Amer. $\Im$.' Dis. Child., 80, 268.

LELONG, M., LAUMONIER, R., and LE TAN VINH (1953), Etudes Néo-Natales, 2, 3.

LEVINE, S. Z., and GORDON, H. H. (1942), Amer. F. Dis. Child., $\vec{c}$ $64,275,297$.

MACGREGOR, A. R. (1939), Arch. Dis. Childh., 14, 323.

MARTIN DU PAN, R., and ROULET, F. (1945), Rev. M Suisse Romande, 65, 146. MILLER, M. D., BEHRLE, F. C., and GIBSON, D. M. (I95D,
Pediatrics, 7, 61 I.

MORRISON, J. E. (1952), 'Foetal and Neonatal Pathology,' London.

POTTER, E. L. (1952), 'Pathology of the Fetus and Newborn,' Chicago.

RHANEY, K., and MACGREGOR, A. R. (1948), Arch. Dis. Childh., 23, 254 .

SMITH, C. A. (1946), 'The Physiology of the Newborn Infant,' Springfield, Illinois.

SNYDER, F. F. (1949), 'Obstetrical Analgesia and Anesthesia,

TRAN-DINH-DE, ANDERSON, G. W. (1953), Obstet. Gynec, Survey, 8, 1 .

TREGILLUS, J. (1951), f. Obstet. Gynec., 58, 406.

WILSON, J. L., LONG, S. B., and HOWARD, P. J. (1942), Amer. $\mathcal{F}$. Dis. Child., 63, 1080.

WINDLE, W. F. (1941), $\mathcal{F}$. Pediat., 19, 437.

\section{RUTHIN CASTLE, NORTH WALES}

A Clinic for the diagnosis and treatment of Internal Diseases (except Mental or Infectious Diseases). The Clinic is provided with a staff of doctors, technicians and nurses.

The surroundings are beautiful. The climate is mild. There is central heating throughout. The annual rainfall is $\mathbf{3 0 . 5}$ inches, that is, less than the average for England.

The Fees are inclusive and vary according to the room occupied.

For particulars apply to THE SECRETARY, Ruthin Castle, North Wales. 